\title{
Otology
}

\section{The impact of intra-operative factors in otosclerosis outcomes: retrospective study in a tertiary centre}

\section{L'impatto dei fattori intra-operatori sul risultato della chirurgia dell'otosclerosi: studio retrospettivo in un centro di terzo livello}

\author{
N. QUARANTA' 1 , K. PICCININNI'1 , M. ROMANELLO², D. LUCIDI², B. SERGI² \\ 1 UOC Otorinolaringoiatria Universitaria, Azienda Ospedaliero-Universitaria Policlinico di Bari, Italy; \\ ${ }^{2}$ UOC Otorinolaringoiatria, Fondazione Policlinico A. Gemelli-IRCSS, Università Cattolica del Sacro Cuore, \\ Rome, Italy
}

\section{SUMMARY}

The aim of the study was to assess results from a large cohort of patients undergoing otosclerosis surgery with respect to the impact of intra-operative variables on post-operative hearing function and complications. We enrolled 384 patients affected by otosclerosis who were subjected to stapes surgery between 2004 and 2013 at a single institution. Surgery was performed in all cases under local anaesthesia, using a manual perforator and/or microdrill. Teflon-piston prosthesis was used in all patients. Audiological data obtained preoperatively and at last follow-up examination (minimum 12 months) were compared. Statistical analysis was performed using the multiple regression model. Peripheral rim otosclerosis and diffuse otosclerosis were associated with better functional results compared to the obliterative pattern $(\mathrm{p}<0.05)$. Mean post-operative Air-Bone Gap was significantly higher in the $0.4 \mathrm{~mm}$, compared to $0.6 \mathrm{~mm}$ piston group at $0.5 \mathrm{kHz}(\mathrm{p}<0.001)$ and $1 \mathrm{kHz}(\mathrm{p}<0.02)$; in the stapedotomy group a statistically significant difference was found between 0.4 and $0.6 \mathrm{~mm}$ piston groups, in favour of the latter $(\mathrm{p}<0.05)$. No differences were encountered in terms of average hearing threshold and complications. Intra-operative variables cannot be fully predictable and our data could help in stratification of the results and as a landmark for the surgeon's decisions.

KEY WORDS: Otosclerosis $\bullet$ Stapedectomy $\bullet$ Stapedotomy $\bullet$ Hearing threshold

\section{RIASSUNTO}

Lo scopo dello studio è stato di valutare i risultati ottenuti in un'ampia coorte di pazienti sottoposti a intervento chirurgico per otosclerosi e determinare l'impatto delle variabili intraoperatorie sulla funzione uditiva e sul tasso di complicanze. Abbiamo arruolato 384 pazienti affetti da otosclerosi e sottoposti a intervento chirurgico tra il 2004 e il 2013 in una singola clinica. L'intervento è stato sempre effettuato in anestesia locale e mediante perforatore manuale elo microdrill. In tutti i pazienti è stata utilizzata una protesi in teflon. I dati audiologici pre-operatori e post-operatori (almeno 12 mesi dopo l'intervento) sono stati confrontati. Le forme di otosclerosi "periferica" e "diffusa" si associavano a migliori risultati funzionali rispetto allo forma “obliterativa” ( $p<0,05)$. L'Air Bone Gap post-operatorio medio risultava significativamente maggiore nel gruppo in cui era stato utilizzato il pistone con diametro 0,4 mm rispetto al gruppo con pistone $0,6 \mathrm{~mm}$ alle frequenze $0,5 \mathrm{kHz}(p<0,001)$ e $1 \mathrm{kHz}(p<0,02)$; nei pazienti sottoposti a stapedotomia è stata riscontrata una differenza statisticamente significativa tra i gruppi in cui era stato utilizzato il pistone da 0,4 e da 0,6 mm, a favore di quest'ultimo $(p<0,05)$. Non sono state riscontrate differenze in termini di soglia uditiva media e di complicanze tra $i$ due gruppi. Le variabili intra-operatorie non sono completamente prevedibili nel pre-operatorio e i nostri dati potrebbero costituire un aiuto nella stratificazione del risultato e come guida per le decisioni del chirurgo.

PAROLE CHIAVE: Otosclerosi $\bullet$ Stapedectomia $\bullet$ Stapedotomia $\bullet$ Soglia uditiva

\section{Introduction}

Otosclerosis is a bone remodelling disorder involving the otic capsule, which leads to a fixation of the stapes footplate and to progressive hearing loss ${ }^{12}$. In 1958 Shea ${ }^{3}$ performed the first total stapedectomy and since then several technological advances have been introduced ${ }^{45}$. Nowadays surgeons may choose among several techniques and materials and the iden- tification of prognostic factors is crucial ${ }^{6-8}$. Surgical technique (stapedotomy versus partial and total stapedectomy) and prosthesis characteristics have been evaluated as prognostic factors ${ }^{9}$. Over the years several prostheses have been proposed in terms of size, material, fixation mechanism and shape. At the present time, reviews show conflicting results regarding the role of piston diameter: Wegner et al. ${ }^{10}$ demon- 
strated that it does not represent a prognostic factor, whereas Laske et al. ${ }^{11}$ reported better outcomes for a $0.6-\mathrm{mm}$ piston. Controversial results have been also reported regarding the surgical technique ${ }^{12-15}$; recently, a meta-analysis on 21 studies ${ }^{16}$ found no evidence for the superiority of laser versus conventional fenestration.

Besides surgical techniques, intrinsic characteristics of the pathology may influence the intra- and post-operative course. Gristwood ${ }^{17}$ classified otosclerosis lesions into 9 types, although he ultimately compared "obliterated" versus "non-obliterated" patterns, demonstrating a better prognosis in the latter group. Portman's classification ${ }^{18}$ includes 5 types of otosclerosis characterised by progressive diffusion of the otosclerotic process, with type 1 corresponding to a small otosclerotic focus, localised at the fissula ante fenestram and type 5 corresponding to a complete obliteration of the footplate and oval window niche. The Portmann classification implies an increasing stapes fixation and surgical risk, based on the extension degree. Malafronte et al. ${ }^{19}$ proposed a simpler classification of otosclerosis, based on the appearance of the stapes footplate: blue footplate, white footplate and obliterative footplate. Identification of colour variation before removal of the superstructure seems to be associated with the incidence of footplate complications. The latter classification refers to histologic patterns and thickness of the footplate (fragile/vitreous versus elastic/ resistant).

The aim of the present study was to evaluate the effect of intra-operative variables on post-operative results and complications in a large cohort of patients affected by otosclerosis and operated on at our Department.

\section{Materials and methods}

From January 2004 to December 2013, 429 consecutive patients were subjected to stapes surgery at the Otolaryngology Unit, University of Bari. All surgical procedures were performed by one surgeon, namely the first author. The diagnosis of otosclerosis was based on normal otoscopic findings, a progressive conductive hearing loss as air conduction pure tone average $>30 \mathrm{~dB}$ in the range of 0.5 to $4 \mathrm{kHz}$ and the absence of cochleostapedial reflexes. Tympanometry was not considered essential for diagnosis since it is almost universally normal or shows stiffness of the ossicular chain. Tympanometric data suggesting otitis media or tympanosclerosis led to exclusion of the surgical candidacy. Pre-operative CT scan was not considered as part of routine evaluation.

Subjects whose audiological reports before and/or after surgical treatment where not available and patients whose follow-up time was less than 12 months were excluded. Patients undergoing revision surgery, affected by tympanosclerosis, congenital anomalies, epitympanic fixation of the malleus or incus were also excluded. We enrolled 384 patients (248 females and 136 males) with a mean age of 47 years (range: 20-75 years) for data analysis. All patients had at least 12 months of post-operative follow-up. The study was approved by the Local Ethical Committee and was conducted in accordance with the ethical standards of the Declaration of Helsinki. Patients received adequate and comprehensible information about the surgical procedures and gave their written consent.

The following factors were evaluated: pre- and post-operative hearing threshold, surgical technique (partial stapedectomy, total stapedectomy, stapedotomy), diameter of the Teflon-piston $(0.6 \mathrm{~mm}$ or $0.4 \mathrm{~mm})$, intra- and post-operative complications (vertigo, facial palsy, tinnitus, sensorineural hearing loss) and type of otosclerosis pattern. Otosclerosis pattern was classified as: peripheral "well-delimited" rim fixation, diffuse and obliterative.

All patients were subjected to standard surgery under local anaesthesia using a transcanal approach as previously reported ${ }^{12}$. The choice between partial stapedectomy (partial posterior platinectomy), or stapedotomy was only based on the amount of footplate that came out using the microhook. In case of obliterative otosclerosis a microdrill was used to perform a stapedotomy. According to the oval window niche anatomy and footplate opening dimensions, a 0.4 or $0.6 \mathrm{~mm}$ Teflon prosthesis was placed directly into the vestibule and the oval window niche was sealed with earlobe fat and blood.

Audiological evaluation was performed according to the guidelines of the American Academy of Otolaryngology Head and Neck Surgery ${ }^{20}$ : average thresholds were calculated at $500 \mathrm{~Hz}, 1 \mathrm{kHz}, 2 \mathrm{kHz}$ and $3 \mathrm{kHz}$. Last follow-up evaluation was performed on average at 30 months after surgery (range: 12-70 months).

\section{Statistical analysis}

Multiple linear regression analysis was performed. Mean post-operative air-bone gap ( $\mathrm{ABG}$ ), high frequency bone conduction (HFBC), calculated as the pre-operative minus the post-operative pure tone bone conduction average, obtained at least 6 weeks after surgery at 1, 2 and $4 \mathrm{kHz}$, bone conduction pure tone average (BCPTA) and pure tone average (PTA) were considered as the dependent variables, whereas independent variables were: type of otosclerosis, type of surgery, diameter of the piston, intra and post-operative complications. ANOVA and Chi-Square test were used to compare the groups. Statistical software (Statistica 8.0) was used for analysis and significance was set for $\mathrm{p}<0.05$. 


\section{Results}

The otosclerosis involved the peripheral rim in 186 patients (48\%), and was diffuse in 172 patients $(45 \%)$ and obliterative in 26 patients $(7 \%)$. One hundred thirty-seven patients underwent partial stapedectomy (35.6\%), 232 patients stapedotomy (60.4\%) and 15 patients (4\%) "unplanned" total stapedectomy, which was usually performed in case of footplate dislocation during surgical manoeuvres. A $0.6 \mathrm{~mm}$ piston was used in 221 patients $(57.4 \%)$ and a $0.4 \mathrm{~mm}$ piston in the remaining 163 patients $(42.6 \%)$. In Table I patients are classified according to the technique and prosthesis diameter. No patients developed major complications such as dead ear or permanent facial palsy; minor complications such as temporary vertigo, tinnitus and facial palsy occurred in 60 patients $(15.6 \%)$ : namely 40 patients developed transient vertigo (10.4\%), 18 transient tinnitus (4.6\%) and 2 transient facial palsy $(0.5 \%)$. All patients recovered within 15 days after surgery.

Overall mean pre-operative air conduction pure tone average (PTA) was $62.21 \mathrm{~dB}$ (range: 32-106; SD: $\pm 14 \mathrm{~dB}$ ), whereas overall mean post-operative air conduction PTA was 36.45 $\mathrm{dB}$ (range: 11-70; SD: $\pm 12 \mathrm{~dB}$ ). Overall mean pre-opera-

Table I. Patient stratification according to surgical technique and prosthesis diameter.

\begin{tabular}{lccc} 
& $\mathbf{0 . 6} \mathbf{~ m m}$ piston & $\mathbf{0 . 4} \mathbf{~ m m ~ p i s t o n}$ & Total \\
Partial stapedectomy & $100(72.9 \%)$ & $37(27 \%)$ & 137 \\
Stapedotomy & $106(\mathbf{4 5 . 6 \% )}$ & $126(54.4 \%)$ & 232 \\
Total stapedectomy & $15(100 \%)$ & $0(0 \%)$ & 15 \\
Total & 221 & 163 & 384 \\
\hline
\end{tabular}

tive $\mathrm{ABG}$ was $33.8 \mathrm{~dB}$ (range: $20-61$; $\mathrm{SD}: \pm 9 \mathrm{~dB}$ ), whereas overall mean post-operative $\mathrm{ABG}$ was $9.5 \mathrm{~dB}$ (range: 0-31; SD: $\pm 6 \mathrm{~dB}$ ). Differences between pre- and post-operative overall PTA and ABG were statistically significant ( $\mathrm{p}=0.003$ and $\mathrm{p}=0.002$ respectively). Mean post-operative ABG gain was $24.3 \mathrm{~dB}$ (range: 0-50; $\mathrm{SD}: \pm 11 \mathrm{~dB}$ ). ABG worsening was never reported. Overall mean pre-operative bone conduction PTA (BCPTA) was $28 \mathrm{~dB}$ (range: 10-66 $\mathrm{dB} ; \mathrm{SD} \pm 11 \mathrm{~dB}$ ), whereas overall mean post-operative $\mathrm{BCP}$ TA was $27 \mathrm{~dB}$ (range: 9-62; SD: $\pm 10 \mathrm{~dB}$ ). The difference between overall pre- and post-operative mean BCPTA was not statistically significant $(\mathrm{p}=0.23)$. Mean pre- and postoperative audiological data, stratified according to otosclerosis pattern, surgical procedure and prosthesis diameter are reported in Table II.

\section{Otosclerosis pattern}

Statistical analysis did not show significant differences between mean post-operative $\mathrm{ABG}$ in peripheral rim versus diffuse otosclerosis (mean post-operative $\mathrm{ABG}=8.6 \mathrm{~dB}$ vs $9.9 \mathrm{~dB}$ respectively; $\mathrm{p}=0.09$ ). Mean post-operative ABG was significantly higher in obliterative otosclerosis (mean post-operative $\mathrm{ABG}=14.07 \mathrm{~dB}$ in the latter group, $\mathrm{p}=0.0003$ ) (Fig. 1). Moreover, in peripheral rim and diffuse otosclerosis mean post-operative BCPTA increased by 2.2 and $2.1 \mathrm{~dB}$, respectively, whereas it decreased by $1.2 \mathrm{~dB}$ in obliterative otosclerosis. The difference was not significant $(p=0.06)$. No statistically significant differences were noted in the prevalence of the surgical technique performed, while a $0.4 \mathrm{~mm}$ prosthesis was used in a significantly higher number of obliterative otosclerosis compared to the other techniques $(p=0.01)$ (Table III).

Table II. Multilinear regression analysis showing mean pre- and post-operative audiological data, stratified according to surgical procedure, prosthesis diameter and otosclerosis pattern.

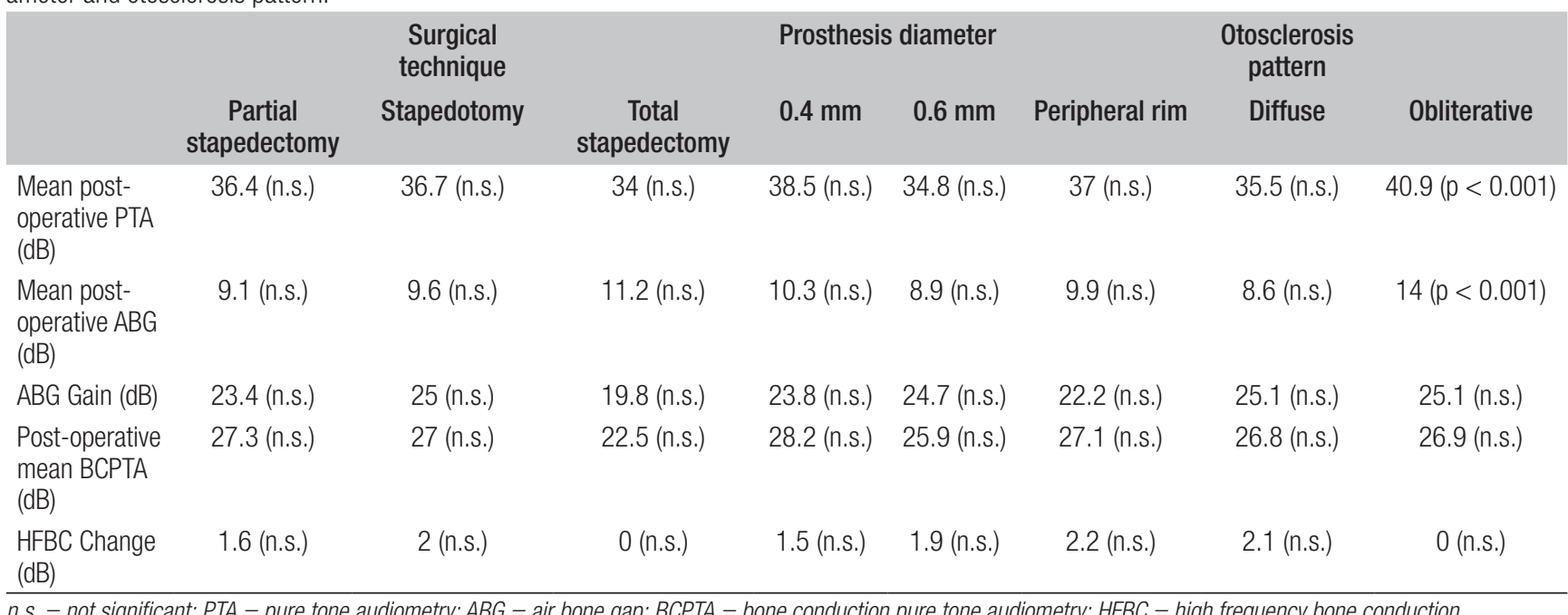




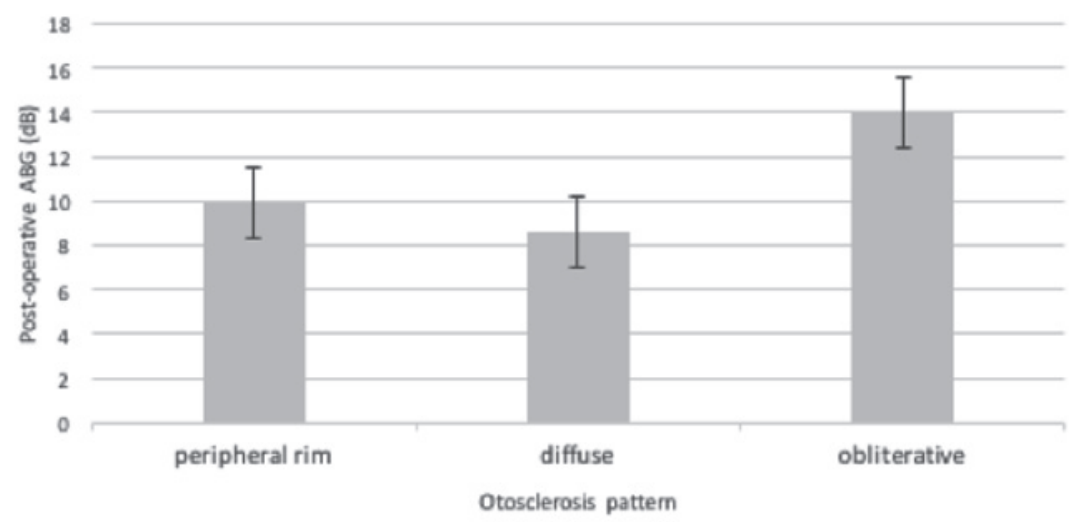

Fig. 1. Comparison of mean post-operative ABG among different otosclerosis patterns (peripheral rim, diffuse and obliterative).

Surgical technique

No significant differences were detected in terms of mean post-operative $\mathrm{ABG}$ according to the type of surgical technique (Fig. 2). In detail, only post-operative $\mathrm{ABG}$ at $0.5 \mathrm{kHz}$ was significantly higher in the stapedotomy group compared to the partial stapedectomy group and the total stapedectomy group (respectively mean post-operative $\mathrm{ABG}=11.2 \mathrm{~dB}$ vs
$8.6 \mathrm{~dB}$ and $8 \mathrm{~dB} ; \mathrm{p}=0.003$ ). No significant differences were encountered in terms of mean post-operative BCPTA change according to the type of surgical technique.

\section{Piston diameter}

No significant differences were found according to the piston diameter in the overall population. Mean post-operative

Table III. Stratification of surgical procedure and diameter of the prosthesis according to the otosclerotic pattern.

\begin{tabular}{|c|c|c|c|c|c|}
\hline & \multicolumn{3}{|c|}{ Surgical technique } & \multicolumn{2}{|c|}{ Prosthesis diameter } \\
\hline & Partial stapedectomy & Stapedotomy & Total stapedectomy & $0.4 \mathrm{~mm}$ & $0.6 \mathrm{~mm}$ \\
\hline Peripheral rim $(n=186)$ & 66 (35.4\%) (n.s.) & 112 (60.3\%) (n.s.) & 8 (4.3\%) (n.s.) & 73 (39.2\%) (n.s.) & 113 (60.8\%) (n.s.) \\
\hline Diffuse $(n=172)$ & $65(37.8 \%)$ (n.s.) & 102 (59.3\%) (n.s.) & $5(2.9 \%)$ (n.s.) & 69 (40.1\%) (n.s.) & 103 (59.9\%) (n.s.) \\
\hline Obliterative ( $n=26$ ) & $6(23 \%)$ (n.s.) & $18(69.2 \%)$ (n.s.) & $2(7.8 \%)$ (n.s.) & $21(80.7 \%)(p<0.05)$ & $5(19.3 \%)(p<0.05)$ \\
\hline
\end{tabular}

n.s.: not significant.

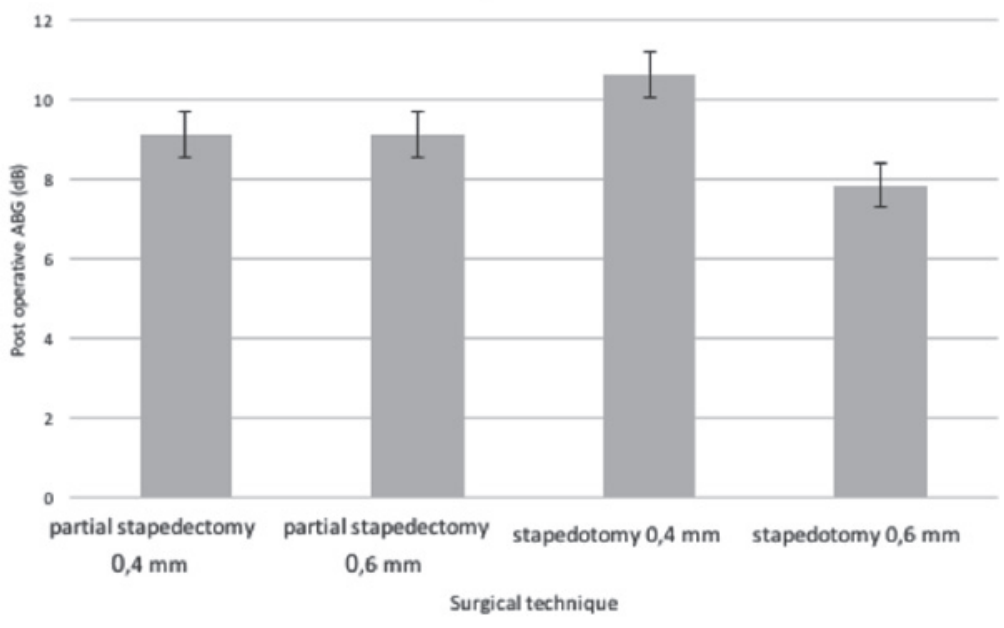

Fig. 2. Mean post-operative $A B G$ according to surgical technique and piston diameter. 
$\mathrm{ABG}$ was significantly higher in the $0.4 \mathrm{~mm}$, compared to $0.6 \mathrm{~mm}$ piston group at $0.5 \mathrm{kHz}(14 \mathrm{~dB}$ vs $7.5 \mathrm{~dB}$ respectively; $\mathrm{p}=0.0001)$ and $1 \mathrm{kHz}$ only $(11.2 \mathrm{~dB}$ vs $9.0 \mathrm{~dB}$ respectively; $p=0.015)$, whereas no significant differences were found at the other frequencies ( $\mathrm{p}=0.1)$ (Fig. 3).

Moreover, in the partial stapedectomy group the mean postoperative ABG did not significantly differ between the 0.4 and $0.6 \mathrm{~mm}$ piston groups $(9.1 \mathrm{~dB}$ in both), while in the stapedotomy group a significant difference was found between 0.4 and $0.6 \mathrm{~mm}$ piston groups in favour of the latter (respectively 10.6 vs $7.83 \mathrm{~dB} ; \mathrm{p}=0.04$ ).

Analysis of mean BCPTA change demonstrated the absence of a significant difference between the $0.4 \mathrm{~mm}$ and $0.6 \mathrm{~mm}$ diameter groups $(\mathrm{p}=0.09)$.

\section{Post-operative complications}

Details regarding the association between complications and surgical variables are reported in Table IV. Temporary complications (namely tinnitus, vertigo and facial palsy) were significantly higher in case of obliterative otosclerosis, 0.6 $\mathrm{mm}$ piston and in patients subjected to total stapedectomy $(\mathrm{p}=0.035)$.

\section{Discussion}

The population of the present study achieved satisfactory functional results, with a mean post-operative $\mathrm{ABG}$ of 9.5 $\mathrm{dB}$ and a post-operative $\mathrm{ABG}$ lower than $20 \mathrm{~dB}$ in $93 \%$ of cases, in agreement with our previous reports ${ }^{12} 21$. Moreover, mean BCPTA improved by $1.7 \mathrm{~dB}$ and permanent complications were never reported.

\section{Otosclerosis pattern}

We adopted a classification based on the Portmann and Malafronte system, to synthesise both anatomical diffusion and histologic appearance. Well delimited rim and diffuse otosclerosis were associated with better hearing results compared to obliterative otosclerosis. "Blue" and "White" patterns, similar to the report by Malafronte et al., do not differ significantly on post-operative hearing function, since significant differences are reported in comparison to the "obliterative" pattern outcome only. An experienced surgeon, in fact, should be able to quickly differentiate, before removal of the superstructure, the intrinsic risk of intra-operative manipulation, according to the macroscopic appearance ${ }^{22}$. Although diffuse otosclerosis is considered as more challenging, specific competence allows to obtain comparable results in diffuse versus limited otosclerotic focus. On the other hand, the greater surgical difficulty of obliterative otosclerosis has been fully described in the literature. Daniels ${ }^{23}$ demonstrated in a large cohort, the higher complexity in the drill-out of the oval window in the obliterative pattern, leading to a significantly lower rate of $\mathrm{ABG}$ closure and higher rate of sensorineural hearing loss when compared to a routine stapedectomy. Also, in our results mean post-operative ABG was significantly higher in obliterative otosclerosis, compared to other

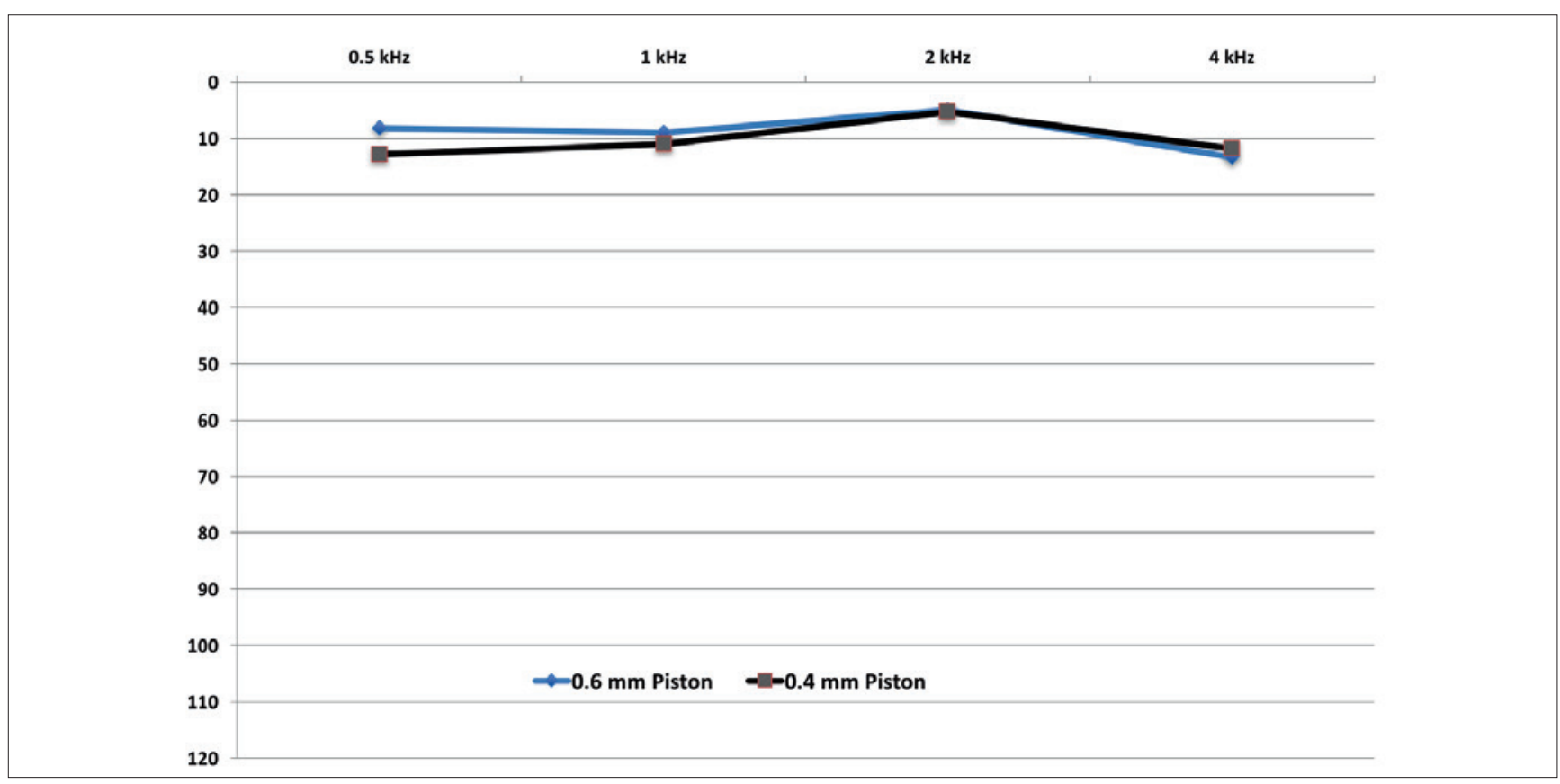

Fig. 3. Comparison of post-operative ABG between $0.4 \mathrm{~mm}$ and $0.6 \mathrm{~mm}$-diameter piston at 0.5, 1, 2 and $4 \mathrm{kHz}$. 
Table. IV. Incidence of temporary complications stratified according to the intra-operative parameters.

\begin{tabular}{|c|c|c|c|c|c|}
\hline & & $\begin{array}{l}\text { Overall } \\
(n=60)\end{array}$ & $\begin{array}{l}\text { Temporary vertigo } \\
\qquad(\mathrm{n}=40)\end{array}$ & $\begin{array}{l}\text { Tinnitus } \\
(n=18)\end{array}$ & $\begin{array}{l}\text { Facial palsy } \\
\quad(n=2)\end{array}$ \\
\hline \multirow[t]{3}{*}{ Surgical technique } & Partial stapedectomy & $\begin{array}{l}26 / 137(18.9 \%) \\
\quad(p<0.05)\end{array}$ & 18/137 (13.1\%) (n.s.) & $\begin{array}{c}7 / 137(5.1 \%) \\
(p<0.05)\end{array}$ & $\begin{array}{c}1 / 137(0.7 \%) \\
\text { (n.s.) }\end{array}$ \\
\hline & Stapedotomy & $\begin{array}{l}29 / 232(12.5 \%) \\
\quad(p<0.05)\end{array}$ & 19/232 (8.1\%) (n.s.) & $\begin{array}{c}9 / 232(3.8 \%) \\
(p<0.05)\end{array}$ & $\begin{array}{c}1 / 137(0.7 \%) \\
\text { (n.s.) }\end{array}$ \\
\hline & Total stapedectomy & $\begin{array}{c}5 / 15(33.3 \%) \\
(p<0.05)\end{array}$ & 3/15 (20\%) (n.s.) & $\begin{array}{c}2 / 15(13.3 \%) \\
(p<0.05)\end{array}$ & $\begin{array}{l}0 / 15(0 \%) \\
\quad \text { (n.s.) }\end{array}$ \\
\hline \multirow[t]{2}{*}{ Prosthesis diameter } & $0.4 \mathrm{~mm}$ & $\begin{array}{c}15 / 163(9.2 \%) \\
(p<0.05)\end{array}$ & 11/163 (6.7\%) (n.s.) & $\begin{array}{c}\text { 3/163 (1.8\%) } \\
\text { (n.s.) }\end{array}$ & $\begin{array}{c}1 / 163(0.6 \%) \\
\quad \text { (n.s.) }\end{array}$ \\
\hline & $0.6 \mathrm{~mm}$ & $\begin{array}{l}45 / 221(20.3 \%) \\
\quad(p<0.05)\end{array}$ & 29/221 (13.1\%) (n.s.) & $\begin{array}{l}15 / 221(6.8 \%) \\
\text { (n.s.) }\end{array}$ & $\begin{array}{l}1 / 221(0.4 \%) \\
\quad \text { (n.s.) }\end{array}$ \\
\hline \multirow[t]{3}{*}{ Otosclerosis pattern } & Peripheral rim & $\begin{array}{l}26 / 186(13.9 \%) \\
\quad(p<0.05)\end{array}$ & $\begin{array}{c}13 / 186(6.9 \%) \\
(p<0.05)\end{array}$ & $\begin{array}{c}\text { 12/186 (6.4\%) } \\
\text { (n.s.) }\end{array}$ & $\begin{array}{l}1 / 186(0.5 \%) \\
\quad \text { (n.s.) }\end{array}$ \\
\hline & Diffuse & $\begin{array}{c}26 / 172(15.1 \%) \\
\quad(p<0.05)\end{array}$ & $\begin{array}{c}20 / 172(11.6 \%) \\
\quad(p<0.05)\end{array}$ & $\begin{array}{c}\text { 5/172 (2.9\%) } \\
\text { (n.s.) }\end{array}$ & $\begin{array}{c}0 / 26(0 \%) \\
\text { (n.s.) }\end{array}$ \\
\hline & Obliterative & $\begin{array}{c}8 / 26(30.7 \%) \\
(p<0.05)\end{array}$ & $\begin{array}{c}7 / 26(26.9 \%) \\
(p<0.05)\end{array}$ & $\begin{array}{c}1 / 26(3.8 \%) \\
\text { (n.s.) }\end{array}$ & $\begin{array}{c}0 / 26(0 \%) \\
\text { (n.s.) }\end{array}$ \\
\hline
\end{tabular}

n.s.: not significant.

patterns, although mean post-operative HFBC only showed a slight decrease, which did not reach statistical significance. Moreover, no difference was found in the choice of the surgical technique in the obliterative pattern vs. the others. We found, however, that in the majority of obliterative cases a $0.4 \mathrm{~mm}$-diameter prosthesis was positioned, with a significantly higher prevalence compared to the other patterns. This might be easily explained by the difficulty encountered in the extensive drill-out of a thick and friable footplate and represents a bias in the assessment of functional results obtained through different prosthesis diameters.

No patients affected by obliterative otosclerosis experienced a permanent complication. However, a significantly higher incidence of temporary complications $(30.7 \%)$ was recorded compared to the other patterns. The most frequent symptom was dizziness, reported by $7 / 26$ patients (26.9\%). These results indicate that extensive drilling might cause a temporary dysfunction of sensory hair cells, leading to transient vertigo and/or tinnitus in a significantly higher percentage of patients. However, this does not translate into permanent inner ear damage, since HFBC remained stable.

\section{Surgical technique}

No functional differences were seen among the three surgical groups, since no statistically significant differences were found in mean post-operative $\mathrm{ABG}$ and $\mathrm{HFBC}$. The significant difference in $\mathrm{ABG}$ at $0.5 \mathrm{kHz}$, in favour of the stapedectomy group, is consistent with reports advocating a slightly better performance obtained in the lower frequencies ${ }^{13-15}$ due to the wider surface of the oval window that is removed. Mean post-operative HFBC change does not differ significantly, according to the surgical technique. Hair cell damage caused by the surgical trauma was similar among the three groups and the greater or smaller surface of restored footplate does not influence post-operative bone conduction ${ }^{15} 24$.

Several studies were conducted regarding comparison of functional outcomes in stapedotomy versus stapedectomy, with controversial results ${ }^{12-15}$. Stapedotomies have been reported in the literature to have better hearing improvements at high frequencies ${ }^{12}$. In other studies, stapedectomies have been advocated for higher hearing improvement at low frequencies ${ }^{13-15}$. In our previous study on 151 subjects ${ }^{12}$, we reported that stapedotomy and partial stapedectomy have equivalent results in term of $\mathrm{ABG}$ closure and air conduction gain in the speech frequencies. However, stapedotomy was associated with better $\mathrm{ABG}$ closure at $4 \mathrm{kHz}, \mathrm{ABG}$ gain at 2,3 , and $4 \mathrm{kHz}$ and greater air conduction gain in the high frequencies (4 to $8 \mathrm{kHz}$ ). Sakamoto et al. ${ }^{25}$ demonstrated, in a 99 ear cohort, that stapedotomies were more effective on global hearing function compared to stapedectomies. Rizer ${ }^{26}$ on the contrary demonstrated better results at $0.5-3 \mathrm{kHz}$ with partial or total stapedectomy compared to stapedotomy. Several authors have shown overlapping hearing outcomes between stapedotomy and partial stapedectomy ${ }^{24}$.

The controversial results obtained in the literature in terms of the "optimal" technique may be influenced by multiple factors such as instruments used to remove the footplate (microhook, perforator, microdrill, lasers), diameter and material of the pistons, vein or connective tissue interposition and 
experience of the surgeon. Moreover, intrinsic bias cannot be avoided since a significant portion of stapedotomies are converted into stapedectomy during the operation and several surgeons prefer to perform stapedotomy selectively in patients with favourable anatomic conditions, whereas stapedectomy is reserved for complicated cases.

The results of the present series show that, among morphological variables, the macroscopic otosclerosis pattern did not influence our choice. In fact, no significant difference exists in the prevalence of various patterns among the three surgical groups (see Table III). In case of total stapedectomy we used a $0.6 \mathrm{~mm}$ diameter prosthesis in all cases, expecting a larger prosthesis, together with a graft composed of earlobe fat and blood, to have more stability in an entirely open oval window. A tendency towards using larger diameter prosthesis is shown even in the partial stapedectomy group, compared to the stapedotomy group (Table I).

Finally, a significant increase of the risk of complications was recorded in the total stapedectomy group $33.3 \%$ of cases) ${ }^{25}$. Both transient vertigo and tinnitus, due to vestibular trauma deriving from the manipulation and total removal of the footplate were reported.

\section{Piston diameter}

We systematically used a Teflon-piston prosthesis in our patients, according to the study by Durko ${ }^{27}$, who considered this material as the best option. A recent review on 12 studies ${ }^{16}$ showed that the majority of those could not show a significant difference between 0.4 and 0.6 pistons. Moreover, differences that were detected were not consistently in favour of a smaller or larger-diameter piston. On the contrary, a meta-analysis by Laske et al. ${ }^{11}$ reported that a $0.6-\mathrm{mm}$ piston is associated with significantly better post-operative $A B G$ at low and mid frequencies, compared to a $0.4 \mathrm{~mm}$ prosthesis. Bernardeschi et al. ${ }^{28}$ demonstrated a significant difference in AC gain, AC threshold at 0.125 and $0.25 \mathrm{kHz}$ and $\mathrm{BC}$ threshold at $0.25 \mathrm{kHz}$ in favour of the $0.6-\mathrm{mm}$ group. The latter study is one of the few to be designed as a prospective one, on consecutive cohorts, with minimum risk of bias.

According to our analysis, no significant difference was seen in mean post-operative $\mathrm{ABG}$ and $\mathrm{HFBC}$ in $0.4 \mathrm{~mm}$ versus $0.6 \mathrm{~mm}$ piston diameter, although the latter provides better $\mathrm{ABG}$ values at low frequencies. Although unanimous consensus has not been reached, it is reasonable to assume that an extremely narrow piston does not effectively transmit sound energy into the vestibule, producing less volume displacement especially at lower frequencies. On the contrary, a larger prosthesis has a larger surface area of transmission. The increased portion of the cochlea stimulated by the prosthesis diameter-to-footplate ratio could explain the better results of pistons with a higher diameter. Experimen- tal studies on temporal bones have demonstrated increased round window velocities and higher perilymphatic volume displacement ${ }^{29}{ }^{30}$ with larger diameter prosthesis. We believe that when anatomical conditions allow a choice, a larger-diameter piston may be preferable.

Our study has some limitations due to the retrospective and non-randomised nature, heterogeneous follow-up duration and intrinsic methodological bias. Several critical procedures were in fact accidentally converted in total stapedectomies, the choice of technique and prosthesis diameter was influenced by anatomic conditions, hearing condition or size of the fenestration. Smaller-diameter pistons are usually preferred in case of unfavourable anatomic conditions (dehiscent/overhanging facial nerve, narrow oval window niche, persistent stapedial artery), affecting the association with hearing outcome. Moreover, functional outcome is influenced by other factors, besides those mentioned above, such as pre-operative threshold, cochlear function, anatomical conditions, experience of the surgeon and efficacy of prosthesis crimping.

\section{Conclusions}

A well-delimited rim and diffuse otosclerosis patterns and $0.6 \mathrm{~mm}$-diameter piston can be considered as factors associated with better outcome. No functional differences were detected when comparing partial stapedectomy, total stapedectomy and stapedotomy. Obliterative otosclerosis represents an unfavourable prognostic factor, although significant sensorineural hearing loss or permanent complications were not recorded. It is not possible, at the state of our knowledge, to pre-operatively predict the extent of the otosclerotic focus, although radiologic and audiometric indicators have been proposed ${ }^{31}{ }^{32}$. In our opinion, the only factor considered as adequate and the less hazardous in possible intra-operative management is the experience of the surgeon.

\section{Conflict of interest statement}

None declared.

\section{References}

1 Menger DJ, Tange RA. The aetiology of otosclerosis: a review of the literature. Clin Otolaryngol Allied Sci 2003;28:112-20.

2 Dispenza F, Cappello F, Kulamarva G, et al. The discovery of stapes. Acta Otorhinolaryngol Ital 2013;33:357-9.

3 Shea JJ Jr. Fenestration of the oval window. Ann Otol Rhinol Laryngol 1958;67:932-51.

4 Somers T, Vercruysse JP, Zarowski A, et al. Stapedotomy with microdrill or carbon dioxide laser: influence on inner ear function. Ann Otol Rhinol Laryngol 2006;115:880-5.

5 Somers T, Vercruysse JP, Zarowski A, et al. Transient depression of in- 
ner ear function after stapedotomy: Skeeter versus CO(2) laser technique. Adv Otorhinolaryngol 2007;65:267-72.

6 Gerard JM, Serry P, Gersdorff MC. Outcome and lack of prognostic factors in stapes surgery. Otol Neurotol 2008;29:290-4.

7 Koopmann M, Weiss D, Savvas E, et al. Outcome measures in stapes surgery: postoperative results are independent from preoperative parameters. Eur Arch Otorhinolaryngol 2015;272:2175-81.

8 Puxeddu R, Ledda GP, Pelagatti CL, et al. Revision stapes surgery for recurrent transmissional hearing loss after stapedectomy and stapedotomy for otosclerosis. Acta Otorhinolaryngol Ital 2005;25:347-52.

9 Motta G, Livi W, Ruosi M. Evolution of the operative technique. CO2 laser stapedotomy and stapedoplasty. Acta Otorhinolaryngol Ital 1996;16:19-27.

10 Wegner I, Verhagen JJ, Stegeman I, et al. A systematic review of the effect of piston diameter in stapes surgery for otosclerosis on hearing results. Laryngoscope 2016;126:182-90.

11 Laske RD, Röösli C, Chatzimichalis MV, et al. The influence of prosthesis diameter in stapes surgery: a meta-analysis and systematic review of the literature. Otol Neurotol 2011;32:520-8.

12 Quaranta N, Besozzi G, Fallacara RA, et al. Air and bone conduction change after stapedotomy and partial stapedectomy for otosclerosis. Otolaryngol Head Neck Surg 2005;133:116-20.

13 Kos MI, Montandon PB, Guyot JP. Short- and long-term results of stapedotomy and stapedectomy with a teflonwire piston prosthesis. Ann Otol Rhinol Laryngol 2001;110:907.

14 Moller P. Stapedectomy versus stapedotomy: a comparison. Rev Laryngol Otol Rhinol (Bord) 1992;113:397-400.

15 Sedwick JD, Louden CL, Shelton C. Stapedectomy vs stapedotomy. Do you really need a laser? Arch Otolaryngol Head Neck Surg 1997;123:177-80.

16 Wegner I, Kamalski DM, Tange RA, et al. Laser versus conventional fenestration in stapedotomy for otosclerosis: a systematic review. Laryngoscope. 2014;124:1687-93.

17 Gristwood RE. Obliterative otosclerosis. An analysis of the clinical and audiometric findings. J Laryngol Otol 1966;80:1115-26.

18 Portmann M. The ear and temporal bone. New York: Mason; 1979.

19 Malafronte G, Filosa B, Cantone E. New macroscopic classification of stapedio-ovalar otosclerosis: a simplified rating for training in stapedotomy. Otol Neurotol 2008; 29:889-92.
20 Committee on Hearing and Equilibrium guidelines for the evaluation of results of treatment of conductive hearing loss. Otolaryngol Head Neck Surg 1995;113:186-7.

21 Sergi B, Lucidi D, De Corso E, et al. Long-term follow-up after "one-shot" CO2 laser stapedotomy: is the functional outcome stable during the years? Eur Arch Otorhinolaryngol 2016;273:3623-9.

22 Sergi B, Paludetti G. Can the learning curve in stapes surgery predict future functional outcome? Acta Otorhinolaryngol Ital 2016;36:135-8.

23 Daniels RL, Krieger LW, Lippy WH. The other ear: findings and results in 1,800 bilateral stapedectomies. Otol Neurotol 2001;22:603-7.

24 Cremers CW, Beusen JM, Huygen PL. Hearing gain after stapedotomy, partial stapedectomy, or total stapedectomy for otosclerosis. Ann Otol Rhinol Laryngol 1991;100:959-61.

25 Sakamoto T, Kikuta S, Kikkawa YS, et al. Differences in postoperative hearing outcomes and vertigo in patients with otosclerosis treated with laser-assisted stapedotomy versus stapedectomy. ORL J Otorhinolaryngol Relat Spec 2015;77:287-93.

26 Rizer FM, Lippy WH. Evolution of techniques of stapedectomy from the total stapedectomy to the small fenestra stapedectomy. Otolaryngol Clin North Am 1993;26:443-51.

27 Durko M, Pajor A, Jankowski A, et al. Does the material of stapes prosthesis influence hearing improvement in stapes surgery - retrospective analysis of 350 cases. Otolaryngol Pol 2008;62:480-2.

28 Bernardeschi D, De Seta D, Canu G, et al. Does the diameter of the stapes prosthesis really matter? A prospective clinical study. Laryngoscope 2018;128:1922-6.

29 Wegner I, Eldaebes MM, Landry TG, et al. The effect of piston diameter in stapedotomy for otosclerosis: a temporal bone model. Otol Neurotol 2016; 37:1497-502.

30 Sim JH, Chatzimichalis M, Röösli C, et al. Objective assessment of stapedotomy surgery from round window motion measurement. Ear Hear 2012;33:24-31.

31 Genç A, Sennaroğlu L. Is it possible to predict diffuse obliterative otosclerosis preoperatively by audiologic examination. Int J Audiol 2007;46:203-7.

32 Veillon F, Riehm S, Emachescu B, et al. Imaging of the windows of the temporal bone. Semin Ultrasound CT MR 2001;22:27180.

Received: November 20, 2017 - Accepted: August 23, 2018

How to cite this article: Quaranta N, Piccininni K, Romanello M, et al. The impact of intra-operative factors in otosclerosis outcomes: retrospective study in a tertiary centre. Acta Otorhinolaryngol Ital 2019;39:197-204. https://doi.org/10.14639/0392-100X-2004

Address for correspondence: Daniela Lucidi, Institute of Otolaryngology, Catholic University of Sacred Heart "A. Gemelli” Hospital, largo Francesco Vito 1, 00168 Rome, Italy. Tel. +39 06 30154439. Fax +39 06 3051194. E-mail: dani.lucidi@ gmail.com 